\title{
Investigation of the Biodynamic Commands Use Effect on Mucilage Content and Germination Behavior in Three Ecotypes of Basil (Ocimum sp.)
}

\author{
Mozhgan Sabet Teimouri ${ }^{1, a^{*}}$ \\ ${ }^{1}$ Academic Centre and Education for Culture and Research, Khorasan Razavi Organization, \\ Mashhad, Iran \\ a*ecotijdm@gmail.com
}

Keywords: Basil, Bio-dynamic, Germination, Mucilage, ecotype.

\begin{abstract}
One of the most popular and usable Aromatic plants are kinds of Basilica (Ocimum sp., Lamiaceae). This genius has different characteristics in behavior germination. Biodynamic agriculture is a new science in the research and especially the position of stars and planet relative to each other, position of moon around the earth and seasonal change and Solar and lunar eclipses. We must demonstrate this theory. In this experiment, we want to record the effect of based on two calendars (biodynamic and Astronomic) on three ecotypes of Basilica seed germination. The base of this experiment was a randomized block design with three replications. We used 50 seeds in Falcon tube (value $=15 \mathrm{ml}$ ) and recorded the weight and value of seeds in tube. Then we added $5 \mathrm{ml}$ of water in tube and shacked after moisturized and control and recorded the Mucilage value and another behavior of seed germination in lab condition. Results showed that different position of some planets such as moon and Mars and Jupiter had the highest effect, positive and significant effect on mucilage percent ( $>>95 \%)$, germination speed and length of root. Therefore, we could express the lunar position had the highest effect on root length of local type and the lowest effect on purple basil. Mucilage percentage of seed coat in green basil had the highest content relative to another ecotype and this content was significant ( $p>95 \%)$. Thus, the best suggestion for the produce of mucilage from the basil seeds, the best time is the first quadrature of the moon.
\end{abstract}

\section{Introduction}

Basil is the most important medicinal plant in around the world and it has many species that in Asia used some famous annual and perennial of them (Ocimum basilicum, Ocimum minimum, Ocimum sanctum). Perennial Basil belongs to the genus Ocimum and is a member of the Mint Family (Lamiaceae). Over 60 varieties of annuals and perennials belong to this genus are native to tropical and subtropical regions around the world [3-4]. This species originated in Egypt and East Mediterranean, but is widely cultivated in Iran, Japan, China and Turkey.

Ocimum species are used in traditional Iranian medicine, as a culinary herb, and as a wellknown source of flavoring principles. Horticultural characteristics, including quantitative and qualitative traits along with the chemical variation of phenolic acids, of 23 accessions of basil (Ocimum basilicum L.) from Iran were studied [4]. Basil has a long history of use as food flavors, perfumes and medicinal values. The essential oil has been used for bringing smell to some medicines, for sterilizing of surgical operation fiber, for production of some veterinary and agricultural medicines [24]. Basil seeds have an aromatic odor and bitter taste. They are used as an essential ingredient in soup, sausages, cheese, cakes and candies. Presently, Iran is an important Basil exporter, constituting 20-40\% of world market [3]. Also, in Iran and some part of Asia, basil's seeds are used in desserts and beverages as a source of dietary fibre [22], and have traditionally been used as natural remedies for the treatment of dyspepsia, ulcers, diarrhea, sore throat, and kidney disease [29].

Sweet basil (Ocimum basilicum L.) is a warm season herb usually propagated from seeds. So that basil establishment is difficult and seed germination may be limited, especially during seeding at cold temperatures [7]. Seeds with mucilage subjected to water stress during imbibition and/or 
incubation germinated faster than those without mucilage [5]. Studies of seed mucilage in a number of species suggest that it has multiple ecological roles dependent on species and their environmental context [26]. The presence of mucilage had the positive effects on seedling development and decreased percent of mortality in drought conditions and plays an important role in seed dispersal, seed hydration via increasing surface contact with the substrate, and can serve as a water reservoir for germination, especially under moisture stress, so that presence of mucilage on seeds during imbibition significantly increased germination percentages under increased water stress [5-6].

Basil seed weight varied between 2.79 to 2.99 gr. under varying condition which one of the reasons is decreased of growing cycle and reduced of seed weight [3]. Basil seeds produce a thick layer of mucilage around the pericarp within minutes after hydration that is most prevalent among plant species adapted to surviving in arid sandy soils, though its significance in determining ecological fitness is unclear, but the ecological importance of seed coat mucilage provided valuable information about its roles in critical stages of the plant life cycle [9-27]. The mucilage produced by seeds is reported to be composed of cell-wall polysaccharides that are deposited in testa pericarp cells during development [9]. The mucilage of basil seeds is held together by columnar structures that unfolded from the pericarp and helped hold and stabilize the mucilage to the outer surface. Hemicelluloses, such as arabinoxylan, xylan, XG, glucomannan, etc., are reported as the component of the seed coat mucilage in some species. The polysaccharides from basil seeds consist mainly of glucomannan (43\%) and 1,4-linked xylan (24.3\%) [22]. In addition, cellulose-directed non-catalytic carbohydrate-binding modules have been demonstrated to recognize components in seed mucilage [10]. Among them, arabinoxylan is commonly observed and the seeds without mucilage were almost 4 times greater than water content of intact seeds because the production of hydrophilic mucilage by pericarp, which are released upon seed hydration, is a commonly found adaptation in angiosperms, known as myxodiaspory [11, 12, 14]. Mucilage is deposited in the apoplast of epidermal cells during differentiation of the seed coat or pericarp, and is released during seed hydration to form a water-containing, gel-like capsule surrounding the seed [8]. Seed mucilage may, by providing a moist environment and maintaining metabolic activity in the seed, promote seed development [27]. The important role of mucilages in germination behavior dependent on species, but seed mucilage is one of physical barrier that inhibits germination by regulates water and oxygen diffusion to the seed embryo [14] and enhances water uptake during germination due to its hygroscopic properties, therefore water absorption is much better than that of non-mucilaginous seeds [27]. Similarly, the result showed that the mucilage content affected in different condition of temperature and soaking duration, so that 1 hour after rainfall in temperate and tropical climates, absorbed water by mucilage remain around the seed [21-25]. Also, seed mucilage can also delay germination by impeding diffusion of oxygen, seed dispersal and defend against pathogens, however, seed mucilage can absorb a large amount of water within a short period of time, which allows strong adherence of seeds to soil particles [27]. Basil seeds mucilage acts as a reservoir to hold loosely bound water at high water potential so it is available for seed germination and early seedling development [7].

Germination is a complex biological process and several factors must work simultaneously for the emergence of a seedling and Basil is sensitive to sowing date. Early sowing in dry land caused to Basil had increased produced seed yield in critical [3]. Results showed that the highest germination percentage of sweet basil (86.66-90.66) occurred at $25-30^{\circ} \mathrm{C}$ [28]. Percentage of germination is one of the most important characteristics of the seeds used for cultivation [30].

The principles of Biodynamic agriculture were first developed in the 1920's as a three-tiered approach to growing that incorporates ecological, social and economic sustainability. A biodynamic farm is consciously ethical in its practices and works to grow health and fertility from within to create the very best in agriculture, food production and nutrition [35]. The planets and constellations are part of our total environment and have obvious major interactions with the Earth which result in our experiencing day and night and the seasons of the year and in biodynamic agriculture we planted and sowed seeds on the astronomical calendar [32]. In zodiac, less obvious is the effect of the moon on the tides of the ocean, groundwater rising to the surface at Full Moon, and extra sap 
leak from plants when pruning at Full Moon [31]. High pressure on farms after fertilizing, chemical toxins, mechanization in intensive agriculture are activity to give more and more agricultural and food products but these proses caused to decrease of biodiversity, soil and water quality and loss of some animals. The farmers over the centuries who observed the sky and the results of their farming activities built up their own library of experience of best times for certain activities [32]. They experienced the subtle, less obvious connections between their earth activities and their observations of the sky [19]. In this condition, some farmers followed another way to produce the healthy food without any bad effect on the earth. Some of them follow traditional behaviors or religious and some farmers follow cosmetic differential and work on lunar calendar. One of the biodynamic calendar is written in India and Nastati goes on to elaborate on his explanation that there are 12 stages of plant development, not just the four stages of root, leaf, flower and fruit [31]. Each of these stages correspond to a constellation in the Zodiac: 1) Aries, Taurus and Gemini influence the vegetative forces; 2) Cancer, Leo and Virgo influence the nutritional value; 3) Libra, Scorpio and Sagittarius gather the forces of dissolution and death; 4) Capricorn, Aquarius and Pisces act on the process of incarnation [32-36]. Thus, the Zodiac represents a cycle during which the form becomes manifest, withdraws, is concealed and is preserved [33]. In the study about effects of a biodynamic sowing calendar on the growth of three basil species, the result showed that the species had the greater impact on the observed parameters than either the biodynamic rhythm (sowing date) or the species and sowing date in combination. The effect of significantly influenced plant height, leaf percentage and essential oil content were under the impact of biodynamic rhythm [34]. Mucilage extracted from basil seeds has high non-gelling and high shear-thinning properties and can be used not only as a fat substitute but also as a surfactant and emulsifier in foods [10]. The dough values were significantly $(\mathrm{P}<0.05)$ different ranging from 53.3 to 62.8 [42].

\section{Theory}

Biodynamic agriculture is a new science in the research and especially the position of stars and planet relative to each other, position of the moon around the earth, seasonal change, Solar and lunar eclipses [20, 31-33]. This is when the moon and Saturn are on opposite sides of the Earth and their respective forces are raying into the Earth from opposite directions. This occurs every 27.5 days [15-19]. Moon forces bring in the calcium processes which are connected to propagation and growth forms, while the Saturn forces bring in the silica processes, which are connected to the building up substance or bulk of the plant in root, leaf and fruit [31]. A strengthening effect was observed when transplanting seedlings during Moon opposite Saturn [16].

Now, around 4200 biodynamic farms in 43 countries with 128000 hectares work under IFOAM, International Biodynamic Organization, Biodynamic farming and gardening associations. As respect, at this decade, people prefer to have healthy products without any additional substrate, poisons or chemical fertilizers. Biodynamic agriculture helps them to produce that. Therefore, the aim of this study was to investigate is there a best imbibition date of Basil seed to produce high quality and quantity of mucilage. We verified with our experiment the biodynamic theory.

\section{Materials and Methods}

In this experiment, we followed two calendars (biodynamic calendar 2014-2018 and Persian Astronomic calendar 2014-2018) for observed and recorded the mucilage content, quality of mucilage and germination behaviour of three ecotypes of Ocimum basilicum seed (Picture 1). We chose the Pisces month of zodiac calendar because that time is suitable for seed product and fruit growth and the Aries is the good time for leaves growth. The best time of sowing or planting date is in a minimum distance of moon from the Earth. At this time, plants growth health on minimum disease condition. The experiment was conducted in laboratory conditions. The experiment started at 9 A.M. on 5 March 2016 (based on Persian Astronomic calendar). Then we started this experiment from 5 March until 20 April 2016 and final control for all treatment on 21 April 2018. 
Endemic Basil is the perennial plant with peppery odorant that we collected seeds from Qeshm Island, South of Iran (Picture 2), purple Basil and Green Basil are annual and bought from Iran SFC company.

In this experiment, we want to record the effect of based on two calendars (biodynamic and Astronomic) on three ecotypes of Basil seed germination.

The base of this experiment was a randomized block design with three replications. To measure the mucilage content, falcon tube (volume $=15 \mathrm{ml}$ ) was used. The weight of 50 basil seeds were measured by a digital scale of 0.001 accuracy. Then the volume of 50 seeds was determined and was added up to $5 \mathrm{ml}$ of water to each tube and shacked after moisturized. After that, mucilage content was controlled and recorded at 10 seconds, 5 minutes and 10 minutes after imbibition. All experiment units were controlled after 20 minutes and 12 hours after imbibition too (Picture 3 ).

We try to achieve the best method for measure of swelling factor and mucilage weight based on some article [37-40]. For this purpose, 1 gr seed measured and recorded value of seeds in a graded tube, then added $5 \mathrm{ml}$. of water $(20 \pm 1)$ and shake falcon tube for 2 minutes. After that, all tubes had standing rest for $12 \mathrm{hrs}$. The study was carried out using a $15 \mathrm{ml}$ graduated falcon tube.

For the initial volume of $1 \mathrm{gm}$ basil seeds was measured. Then $15 \mathrm{ml}$ water was added that caused to swollen volume of the seed in room temperature and mucilage content was measured after 12 hours, the swelling index was calculated as [41]:

$$
\text { Swelling index }=[(\mathrm{V} 2-\mathrm{V} 1) / \mathrm{V} 1]^{*} 100 \text {. }
$$

In this formula: V1 is seed volume before hydration, V2 is a volume of hydrated seed after imbibition.

Also, swellings content percent per gram mucilage calculated by:

Swellings content percent $=($ swellings factor/mucilage content $) * 100$.

That way, seeds must to separate from mucilage. To precipitate of mucilage was added $1 \mathrm{ml}$ of Ethanol (96\%) to the mucilage content and tubes were kept in a refrigerator for 6 hours then separated the seeds from mucilage. Finally, mucilage materials were transferred to filter paper and then dried for 30 minutes in an oven at $200{ }^{\circ} \mathrm{C}$ and then dry weight of mucilage was determined.
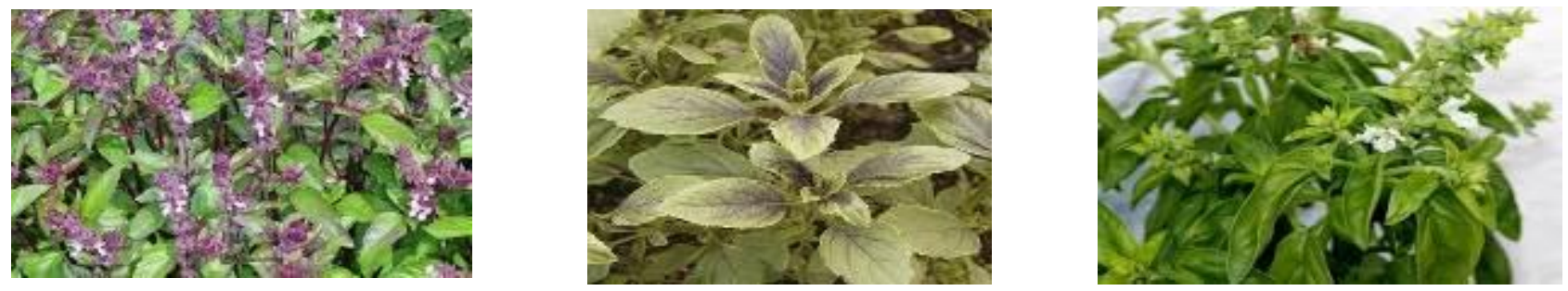

Picture 1. Left to right are 3 types of Ocimum basilicum that be used in this experiment.

a) Endemic Basil, perennial with peppery odorant from Qeshm Island, south of Iran,

b) purple Basil, annual, from SFC company, Iran, c) Green Basil, annual, from SFC company, Iran. 


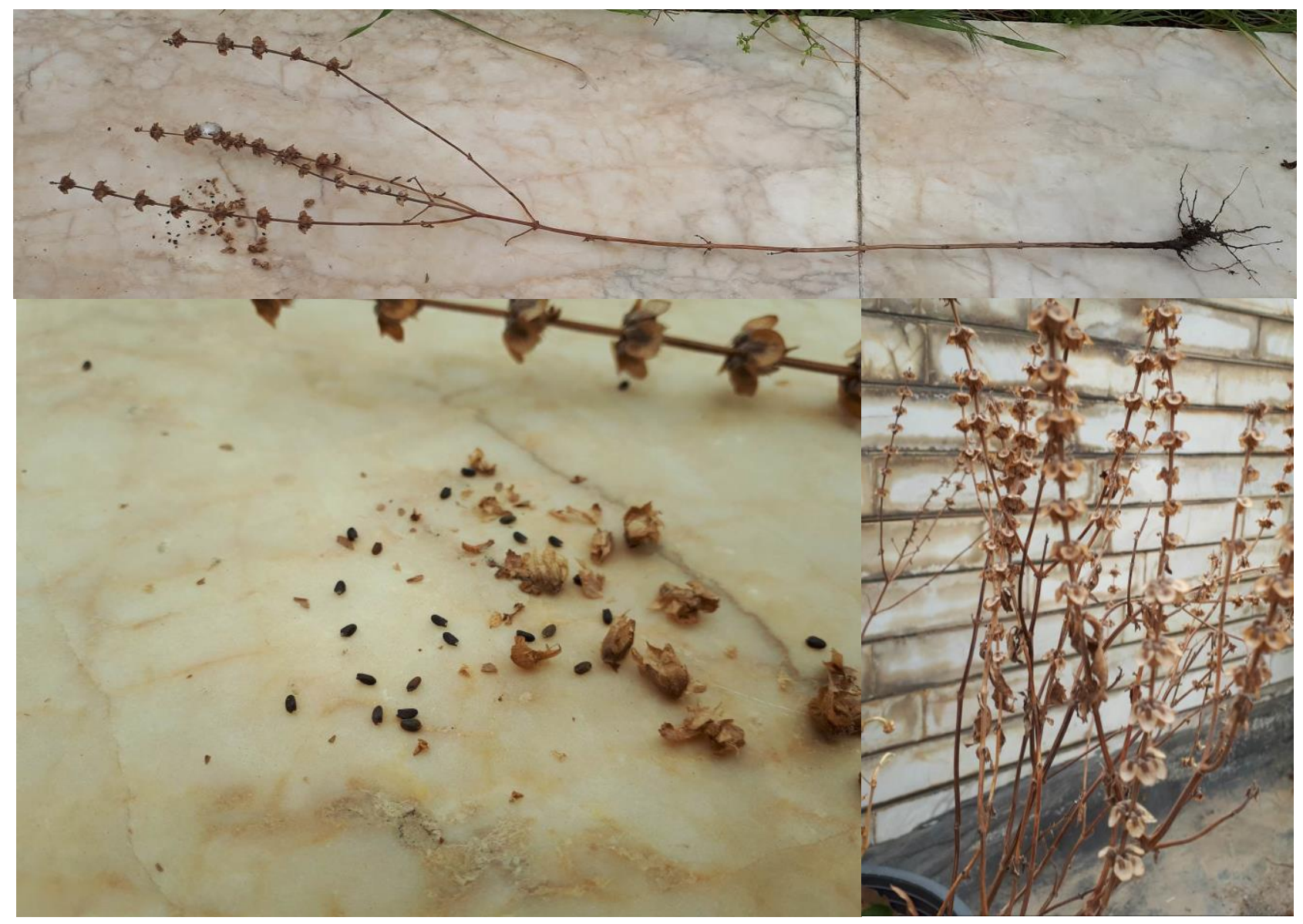

Picture 2. Perennial Basil after seed ripening in autumn 2017.

\section{Results}

Comparative Mucilage quality of three types of Ocimum sp. (Basil) after 1 year from the beginning of the experiment is shown in Pictures 4-6.
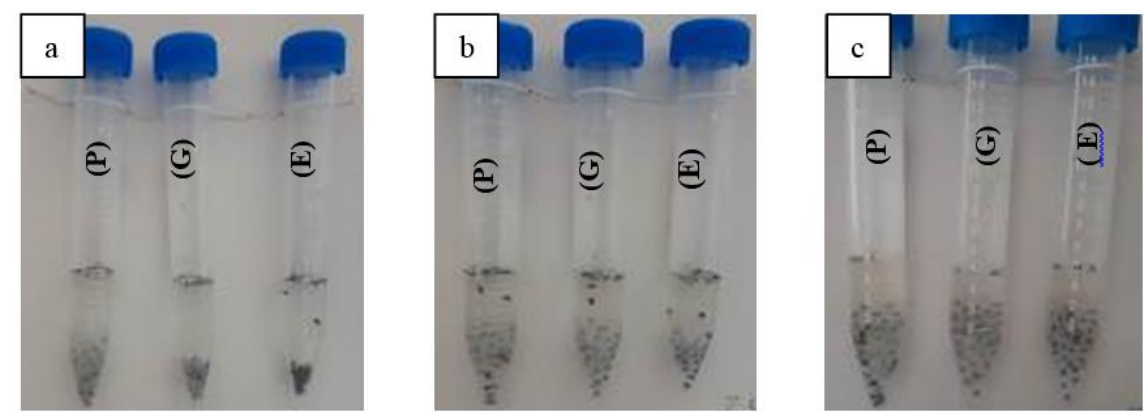

Picture 3. The seed value of mucilage after different imbibition time ( $1^{\text {st }}$ April 2018)

in three ecotypes of Basil ((P) Purple basil- (G) Green Basil- (E) Endemic basil),

a) Left to right imbibition time after $10 \mathrm{~min} ., 5 \mathrm{~min}$. and $10 \mathrm{sec}$., b) three ecotypes of Basil, 20 min after imbibition, c) three ecotypes of Basil, 12 hours after imbibition.

Table 1. Analysis of Variance for the experiment

\begin{tabular}{|l|l|l|l|l|l|}
\hline Source & DF & Adj. SS & Adj. MS & F-Value & P-Value \\
\hline Replication & 2 & 0.0181 & 0.00903 & 0.08 & 0.923 \\
\hline Ecotype & 2 & 1.6674 & 0.83368 & 7.41 & 0.001 \\
\hline Imbibition time & 13 & 54.6681 & 4.20524 & 37.39 & 0.000 \\
\hline Error & 108 & 12.1474 & 0.11248 & & \\
\hline Total & 125 & 68.5010 & & & \\
\hline
\end{tabular}


Table 2. The characteristics of three ecotypes of seed Basil.

\begin{tabular}{|l|c|c|c|c|c|c|}
\hline \multicolumn{1}{|c|}{ Ecotype } & $\begin{array}{c}\text { 100 Seed } \\
\text { weight } \\
\text { [gr] }\end{array}$ & $\begin{array}{c}\text { Value of } \\
\text { 1gr seed } \\
\text { [ml] }\end{array}$ & $\begin{array}{c}\text { Mucilage } \\
\text { value of 1 gr } \\
\text { seed [ml] }\end{array}$ & $\begin{array}{c}\text { Swelling } \\
\text { factor }\end{array}$ & $\begin{array}{c}\text { Dry } \\
\text { mucilage } \\
\text { content } \\
\text { [gr] }\end{array}$ & $\begin{array}{c}\text { Weight of } \\
\text { 10 ml } \\
\text { mucilage } \\
\text { [gr] }\end{array}$ \\
\hline Endemic Basil & 0.14 & 2 & 45 & 2150 & 0.9 & 9 \\
\hline Green Basil & 0.13 & 1.1 & 44 & 3900 & 0.93 & 9 \\
\hline Purple Basil & 0.13 & 1.1 & 39 & 3445 & 0.82 & 9 \\
\hline
\end{tabular}

Table 3. The seedling characteristics of three ecotypes of Basil 72 hours after imbibition.

\begin{tabular}{|l|c|c|c|c|}
\hline \multicolumn{1}{|c|}{ Ecotype } & $\begin{array}{c}\text { Shoot } \\
\text { weight } \\
\text { [gr] }\end{array}$ & $\begin{array}{c}\text { Root } \\
\text { weight } \\
\text { [gr] }\end{array}$ & $\begin{array}{c}\text { Seedling } \\
\text { weight } \\
\text { [gr] }\end{array}$ & $\begin{array}{c}\text { Root/Shoot } \\
\text { weight }\end{array}$ \\
\hline Endemic Basil & 0.22 & 0.10 & 0.30 & 0.45 \\
\hline Green Basil & 0.20 & 0.08 & 0.30 & 0.40 \\
\hline Purple Basil & 0.20 & 0.10 & 0.40 & 0.50 \\
\hline
\end{tabular}

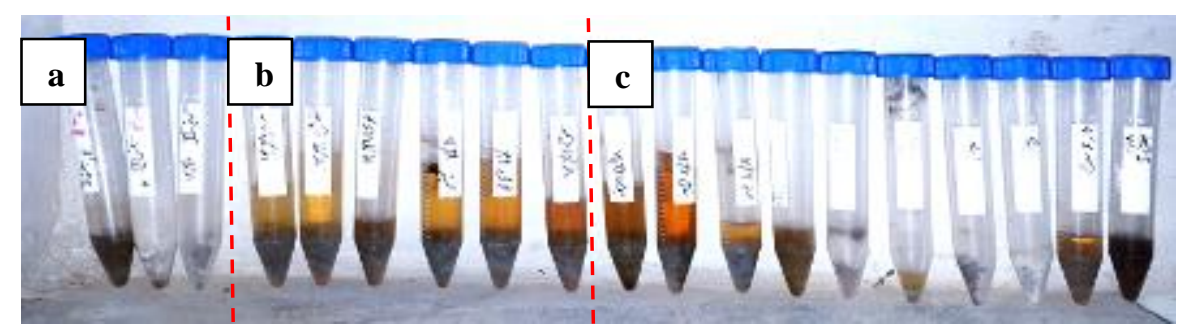

Picture 4. a) 11-12 March (new Moon); b) 15-16 March (moon opposite Saturn); c) 25-26 March 2016 (first quarter) 46 days after first imbibition.

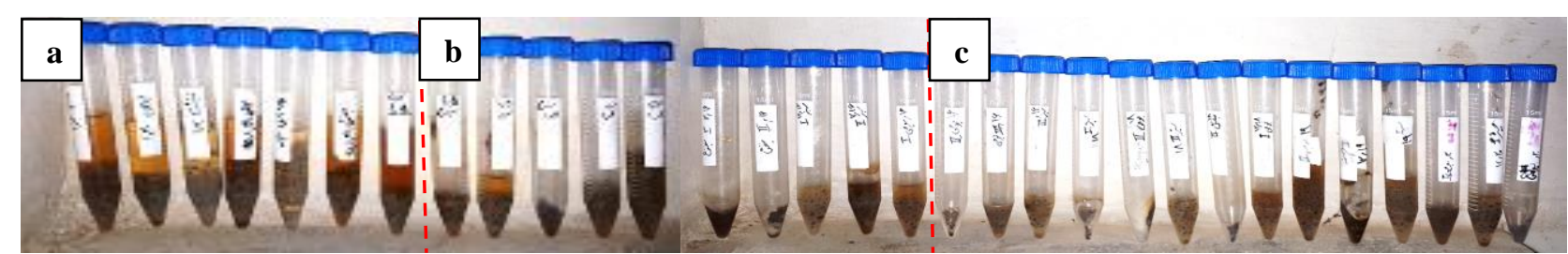

Picture 5. Characteristic of mucilage in different imbibition time after 2 years,

a) new moon imbibition time; b) full moon imbibition time;

c) last quarter imbibition time, 46 days after first imbibition. 


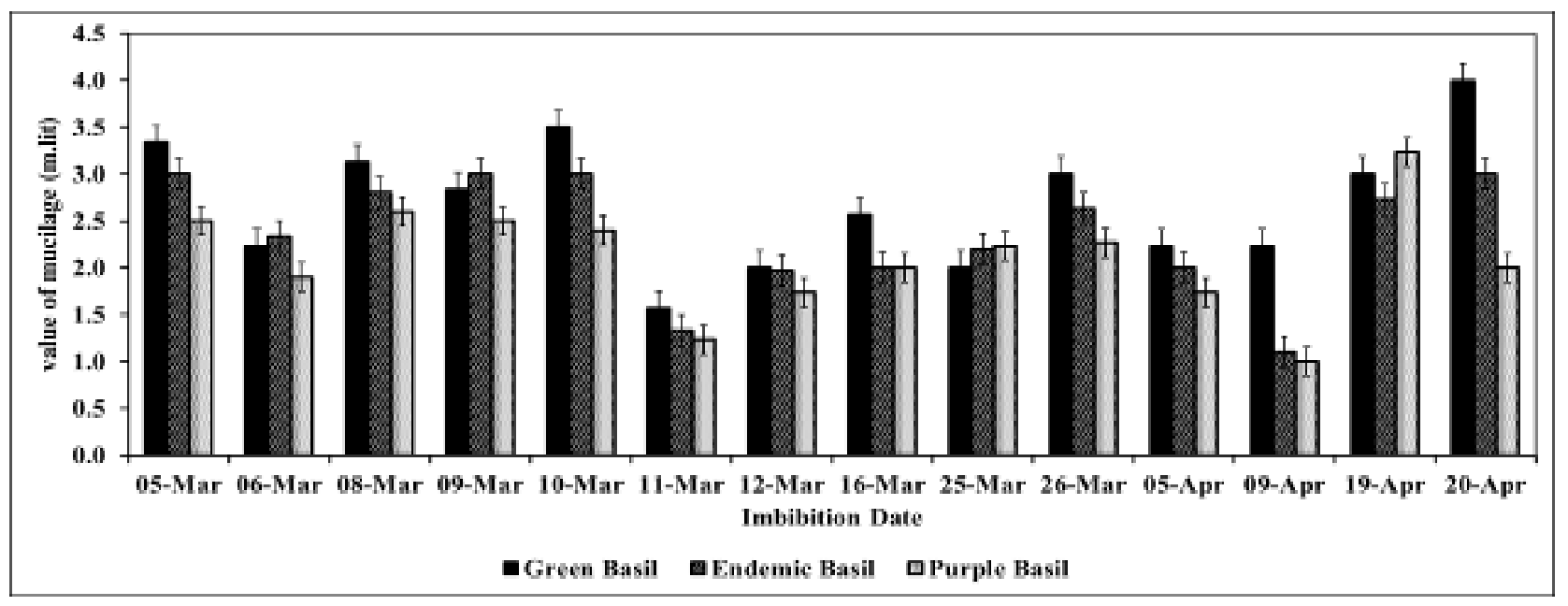

Figure 1. Mucilage content of three types of Basil seed after 30 minutes.

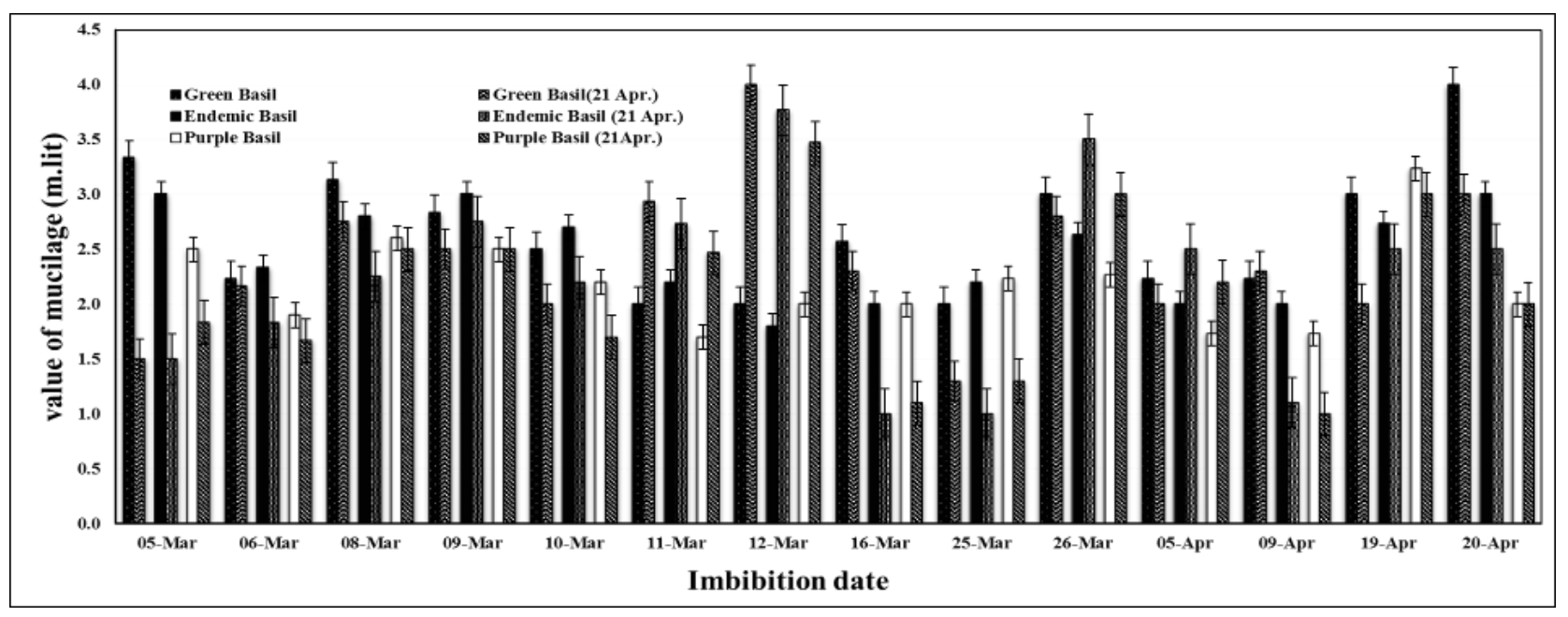

Figure 2. Comparative Mucilage content of 3 types of Ocimum sp. (Basil) after 46 days from starts.

The based on these results, the least of mucilage value was observed in purple basil and the green basil had the highest value of mucilage content (Fig. 1). It seems that the thickness of seed coat of purple basil or the content of water-soluble compounds in there is less than that of green basil.

In all dates instead of 11 and 12 March (new Moon and the nearest position from the Earth) mucilage content decreased at after seed imbibition time. This result was observed in other reports $[15,19,20,33-35]$. Perhaps this is due to the greater impact of the gravity of the moon and the earth at the same time, which can reduce the penetration of water into the seed coat and reduce the dissolution of the existing materials, thereby reducing the volume of mucilage layer, and it seems that date to produce of mucilage is not suitable.

The swellings content percentage of $1 \mathrm{gr}$ seed (550 seeds) was increased by more than $50 \%$. So, after water absorption, the volume of $2 \mathrm{ml}$ of seed increased to $45 \mathrm{ml}$ (Table 2). mucilage

After mucilage drying, this volume of wet mucilage $(8.2 \mathrm{gr})$ decreased to 0.9 gr dried pure 

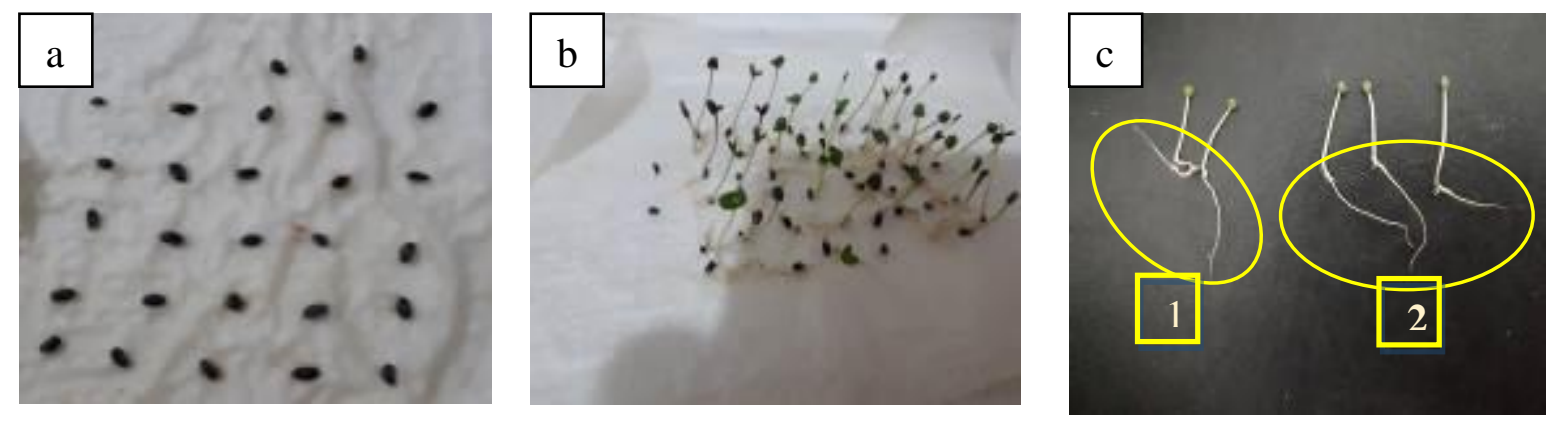

Picture 6. a) 21 days after imbibition at new moon soaking; b) 5 days after imbibition time at full moon; c) one root shape in the first quarter of moon, c) two root shape in full moon.

The results showed that the rate of shoot/root was 2 for all ecotypes on full moon time imbibition and plant weight of purple basil was greater than green basil and endemic basil at this time. In the first quarter of moon the rate of shoot/root was 1.4 and in the first quarter of moon, curly root and short shoot were observed (Table 3).

Results showed that different position of some planets such as moon, Mars and Jupiter had the highest effect, positive and significant effect on mucilage percent ( $\mathrm{p}>95 \%)$, germination speed and length of root (Table 2 and Table 3).

Therefore, we could be express the lunar position had the highest effect on root length of local type and the lowest effect on purple basil.

Mucilage percentage of seed coat in green basil had the highest content relative to another ecotype and this content was significant ( $p>95 \%$ ).

Then, the best suggestion for the produce of mucilage from the basil seeds, the best time is the first quadrature of the moon.

\section{Discussion}

Based on the results of this study, we can see the direct effect of the planet's position on Earth on germination behaviours and basil mucilage quality characteristics. However, in order to increase the accuracy of the results, it needs to ensure more replications in different geographical locations.

\section{Conclusions}

This study showed that the lunar position effected on germination behavior and mucilage content after imbibition. Therefore, in full moon time imbibition, the rate of shoot/root in all ecotypes was 2 and these results explain the positive effect of lunar gravity on root growth that is very important for growing of plants but in basil we need to improve leaf and shoot part. The plant weight of purple basil was more than green basil and endemic basil. In the first quarter of the moon, the rate of shoot/root in all ecotypes was 1.4. In the first quarter of the moon, it was observed curly root and short shoot in three ecotypes of basil. Based on these results, we could accept the effect of imbibition time on germination behaviour, shoot and root shape.

Results showed that different position of some planets such as moon, Mars and Jupiter had the highest positive and significant effect on mucilage percent ( $p>0.95)$, germination speed and length of root. Therefore, we could express the lunar position had the highest effect on root length of local type and the lowest effect on purple basil. Mucilage percentage of seed coat in green basil had the highest content relative to another ecotype and this content was significant ( $>95 \%)$. Then, in the first quadrature of moon it was the best time for the produce of basil mucilage seeds.

Finally, the best quality and quantity of mucilage could be product in the first quarter of the moon.

Due to the lack of similar studies, it is not possible to compare, but according to the results of numerous experiments on the effect of astronomical changes on the germination behaviour of different plants, this theory can be confirmed. 


\section{Conflict of Interest}

The author declares that there is no conflict of interest.

\section{Acknowledgements} ACECR.

Thanks for biodynamic association and Dr. Janpour from biotechnology Department of

\section{References}

[1] J.L. Harper, R.A. Benton, The Behaviour of Seeds in Soil: II. The Germination of Seeds on the Surface of a Water Supplying Substrate, Journal of Ecology. 54(1) (1966) 151-166.

[2] JA.Young, RA. Evans, Mucilaginous seed coats, Weed Sci. Soc. Am. 21 (1973) 52-54.

[3] S. Sadeghi, A. Rahnavard, Z.Y. Ashrafi, The effect of plant-density and sowing-date on yield of Basil (Ocimum basilicum L.) in Iran, Journal of Agricultural Technology. 5(2) (2009) 413422.

[4] J. Javanmardi et al., Chemical characterization of basil (Ocimum basilicum L.) found in local accessions and used in traditional medicines in Iran, J. Agric. Food Chem. 50(21) (2002) $5878-5883$.

[5] S. Ying et al., Role of mucilage in seed dispersal and germination of the annual ephemeral Alyssum minus (Brassicaceae), Australian Journal of Botany. 60(5) (2012) 439-449.

[6] N.C. Garwood, The role of mucilage in the germination of cuipo, cavanillesia platanifolia (H. \& B.) H. B. K. (bombacaceae), a tropical tree, American Journal of Botany. 72 (1985) 10951105 .

[7] Zh. Dongfang, Seed Germination performance and mucilage production of sweet basil (Ocimum basilicum L.), Master science thesis, Virginia Polytechnic Institute and State University, Blacksburg, Virginia, 2012.

[8] T.L. Western, The sticky tale of seed coat mucilages: production, genetics, and role in seed germination and dispersal. Seed Science Research. 22 (2012) 1-25.

[9] S.M. Razavi et al., Optimisation study of gum extraction from basil seeds (Ocimum basilicum L.), International Journal of Food Science and Technology. 44 (2009) 1755-1762.

[10] A.W. Blake et al., Understanding the biological rationale for the diversity of cellulosedirected carbohydrate-binding molecules in prokaryotic enzymes, Journal of Biological Chemistry. 281 (2006) 29321-29329.

[11] T.L. Western, The sticky tale of seed coat mucilages: production, genetics, and role in seed germination and dispersal, Seed Science Research. 22 (2012) 1-25.

[12] S.M.A. Razavi et al., Optimisation study of gum extraction from basil seeds (Ocimum basilicum L.), International Journal of Food Science and Technology. 44 (2009) 1755-1762.

[13] M.A. Dorry, M. Alamdar, Effect of seed rate and planting date on seed mucilage amount of Palntago ovata in dry farming condition, Pazhouhesh and Sazandegi. 20 (2007).

[14] D. Huang et al., Differentiation of the seed coat and composition of the mucilage of Lepidium perfoliatum L.: a desert annual with typical myxospermy, Acta Biochim Biophys Sin. 47(10) (2015) 775-787.

[15] B. Thakore, D. Anderle, Biodynamic calendar of India, Bio-Dynamic Association of India, 2018.

[16] A. Hosseini, M. Nojoomi, Astronomical calendar of Iran, (2015). 
[17] A. Hosseini, M. Nojoomi, Astronomical calendar of Iran, (2016).

[18] H. Jaanghorbani, Astronomical calendar of Iran, (2018).

[19] R. Pomeroy, Networks [Online]. Available: https://www. biodynamics.in/calendar.htm.

[20] R. Steiner, Biodynamic Agriculture, 1924.

[21] S. Nazir, I.A. Wani, F.A. Masoodi, Extraction optimization of mucilage from Basil (Ocimum basilicum L.) seeds using response surface methodology, Journal of Advanced Research. 8(3) (2017) 235-244.

[22] K.Y. Song et al., Effects of Basil (Ocimum basilicum L.) Seed mucilage substituted for fat source in sponge cake: physicochemical, structural, and retrogradation properties, Italian Journal of Food Science. 29(4) (2017).

[23] M. Saeedi et al., Evaluation of Ocimum basilicum L. seed mucilage as rate controlling matrix for sustained release of propranolol $\mathrm{HCl}$, Pharmaceutical and Biomedical Research. 1(1) (2015) 18-25.

[24] J.E. Simon et al., Basil: A source of aroma compounds and a popular culinary and ornamental herb, in: J. Janick (Ed.), Perspectives on New Crops and New Uses, 1999, pp. 499-505.

[25] M. Engelbrecht, E. Bochet, P. García-Fayos, Mucilage secretion: an adaptive mechanism to reduce seed removal by soil erosion?, Biological Journal of the Linnean Society. 111 (2014) 241-251.

[26] D. Barrios et al., The role of mucilage in the germination of Leptocereus scopulophilus (Cactaceae) seeds from Pan de Matanzas, Cuba, Botany. 93(4) (2015) 251-255.

[27] X. Yang et al., More than just a coating: Ecological importance, taxonomic occurrence and phylogenetic relationships of seed coat mucilage, Perspectives in Plant Ecology, Evolution and Systematics. 14 (2012) 434-442.

[28] S. Mijani et al., Seed Germination and Early Growth Responses of Hyssop, Sweet Basil and Oregano to Temperature Levels Notulae Scientia Biologicae. 5(4) (2013) 462-467.

[29] S.H. Hosseini-Parvar et al., Steady shear flow behavior of gum extracted from Ocimum basilicum L. seed: Effect of concentration and temperature, Journal of Food Engineering. 101 (2010) 236-243.

[30] B. Kumar, Prediction of germination potential in seeds of Indian basil (Ocimum basilicum L.), Journal of Crop Improvement. 26 (2012) 532-539.

[31] R. Steiner, Geisteswissenschaftliche Grundlagen zum Gedeihen der Landwirtschaft, Rudolf Steiner Verlag, Dornach, 1924.

[32] M. Sabet Teimouri, Biodinamic Agriculture (in persian), Behta Pazhouhesh press, 2015, pp. 41-58.

[33] M.Thun, Result from the biodynamic swing and planting calendar, Floris books, 2003.

[34] S. Dudaš et al., Effects of biodynamic production on growth and essential oil content in basil, Acta Bot. Croat. 75(2) (2016) 260-265.

[35] Biodynamic products, ARBICO Organics, 2018. [Online] Available: www.arbicoorganics.com.

[36] R. Tayler, C. Gomez, Biodynamic Seed Regeneration: Enabling the Flow of Life Forces in Nature, (online), https://planting-calendar.com, (2015).

[37] P.V. Kadam et al., Evaluation of Ocimum sanctum and Ocimum basillicum Mucilage- As a Pharmaceutical Excipient, Journal of Chemical and Pharmaceutical Research. 4(4) (2012) 1950-1955. 
[38] A. Lotfi et al., The effect of deficit irrigation and manure on quantity and quality traits of plantago ovata Forssk. in Sistan region, Iranian Journal of Medicinal and Aromatic Plants. 24(4) (2009) 506-518.

[39] R. Tiwari, Studies on genetic variability in Isabgol (Plantago ovata Forsk.), MS.C. thesis, The Jawaharlal Nehru Krishi, 2003.

[40] P.K. Sharma, A.K. Koul, Musilage in seed of Plantago ovata and its wild allies, J. Ethnopharmacology. 17 (1986) 289-295.

[41] M. Karan, A. Gurpreet, S. Inderbir, Ocimum Sanctum seeds, a natural superdisintegrant: formulation and evaluation of fast melt tablets of nimesulide, Polim. Med. 42(1) (2012) 4959.

[42] T. Hejrani et al., Impact of the Basil and Balangu gums on physicochemical properties of part baked frozen Barbari bread, Information Processing in Agriculture. Doi: https://doi.org/10.1016/j.inpa.2018.11.004. 